\title{
Treatment of Cognitive Impairment Using a Computer Program in Patients with Depression in Remission
}

\author{
Yépez Norma ${ }^{1}$, Cortés Jacqueline ${ }^{1}$, Álvarez Luz María ${ }^{1}$, Cortés-Sotres José Francisco ${ }^{2}$, \\ Heinze Gerhard ${ }^{3}$, \\ ${ }^{1}$ Psychiatry and Mental Health Department, Faculty of Medicine, National Autonomous University of Mexico, Mexico, Mexico \\ ${ }^{2}$ National Institute of Psychiatry “Ramón de la Fuente Muñiz”, Mexico, Mexico \\ ${ }^{3}$ Postgraduate Studies Division, National Autonomous University of Mexico, Mexico, Mexico
}

\section{Email address:}

normayepez@yahoo.com.mx(Yépez N.),jacqueline_morelos@yahoo.com.mx(Cortés J.), lmalvarezp@yahoo.com(ÁlvarezL. M.), cortess@imp.edu.mx (Cortés-Sotres J.F.), heinzeg@liceaga.facmed.unam.mx (Heinze G.)

*Corresponding author

\section{To cite this article:}

Yépez Norma, Cortés Jacqueline, Álvarez Luz María, Cortés-Sotres José Francisco, Heinze Gerhard. Treatment of Cognitive Impairment Using a Computer Program in Patients with Depression in Remission. American Journal of Applied Psychology.

Vol. 7, No. 2, 2018, pp. 29-36. doi: 10.11648/j.ajap.20180702.11

Received: March 17, 2018; Accepted: April 8, 2018; Published: May 11, 2018

\begin{abstract}
The patient with depressive disorder presents a cognitive impairment which does not disappear despite the fact that the depression is considered to be in remission. This study aims to assess the impact of training in the improvement of cognitive functions of patients with remitted depression (RD). Captain's Log Computerized Cognitive-Training Program (CLCT) was used as a cognitive trainer in a group of patients with RD and with Selective serotonin reuptake inhibitors (SSRI) as treatment; another group with RD was treated uniquely with SSRI. The treatment intervention's impact was evaluated using the Hamilton Rating Scales for Anxiety and Depression, the Wechsler Adult Intelligence Scale (WAIS-III), and the Integrated Program of Neuropsychological Examination-Revised Barcelona Test. CLCT was used in college students with RD, twice a week, for six months. Patients from both groups decreased depressive and anxious symptoms, however, patients who received CLCT substantially increased their intellectual performance; changes in the psychometric analysis of the Barcelona Test were consistent with the ones presented in WAIS-III. CLCT application is associated with an improvement of cognitive functions in patients with RD.
\end{abstract}

Keywords: Depression, Remission, Cognitive Functions, Cognitive Stimulation, College Students

\section{Introduction}

The objective of this trial is to improve cognitive functions in individuals with RD, using Captain's Log Computerized Cognitive-Training Program (CLCT) [1].The World Health Organization (WHO) points that $15 \%$ of the population of developed countries suffer from severe depression, and identified that $30 \%$ of women are depressed [2].

In Mexico, 9 to $13 \%$ of the adult population suffers from depression, with a prevalence of 2 to 1 regarding women and men [3]. This disorder is more frequent among 15-19- yearold individuals and above 65 years, where the recurrence rate is $59 \%$ [4].

In the age group corresponding to university students, a prevalence of $6.2 \%$ was determined in students of the first two years of Medicine. In 2005, Manelic and Ortega-Soto [5], assessed the prevalence of depression in the Faculty of Superior Studies of Aragon of the National Autonomous University of Mexico (UNAM) in $11.8 \%$. Among the University of Colima, the prevalence of depression was about $21.8 \%$ in students of nursing school [6].

Reference [7] found that $92 \%$ of university students who suffered from depression showed academic impairment, in such a way that a student's negative perception of their academic competence represents a risk factor for depression. [8]. Depression in university students affects their academic productivity, school satisfaction, and social relationships, generating stress and enhancing the depressive state [9]. 
Trials like the one performed by Furr, Westefeld, McConnel \& Jenkins in the year of 2001 [10], have reported that depression affects near of $50 \%$ of the university population, stating that multiple factors can contribute to the presentation of depressive symptoms. The most common elements are decreased academic productivity, social stressors, economic problems, and the inherent adjustment of family context to the university environment.

Patients with major depression disorder (MDD) show cognitive deficits [11]. For instance, failures in executive functions such as cognitive flexibility, problem-solving [12], processing speed [13], deficits in domains in memory [14, 15] and deficits in the domain of attention, concentration [14]. As a consequence of these failures, depression also may cause disabilities in cognitive functioning which may drive patients to show social, working performance, academic and intellectual impairment.

Among depressed patients, psychomotor retardation was the most critical factor in work reduction. Authors like Mintz J., Mintz L., Arruda, and Hwang [16] evaluated the effects of anti-depressants and psychotherapy on work impairment in depressed patients. Original databases from 10 published treatment studies were compiled and analyzed $(\mathrm{N}=827)$. Functional work impairment was common at baseline, manifested by unemployment $(11 \%)$ or on-the-job performance problems (absenteeism, decreased productivity, interpersonal problems, $44 \%$ ), only $55 \%$ fulfilled the criteria required to go back to work after treatment.

Academic deterioration is evidenced mainly in absenteeism, low academic performance, poor interpersonal relationships and wrong perception of academic competence. Reference [17] presented a linear structural model which co-relates children's school performance with anxiety and depression. Using intellectual quotient as the control variable of the model the academic performance showed an association between the severity of depression and the child's isolation due to his/her classroom execution and cognitive functioning. Children who were most depressed presented deficiencies in cognitive functioning, and those more introverted had the worst performance in the classroom. On the other hand, depression in university students affects academic performance, satisfaction with studies and social relationships which, in turn, generate stress and thus reinforce the depressive state [18]; reference [7] found out that $92 \%$ of the students diagnosed with depression presented academic impairment.

Cognitive damage persists despite the remission of depressive symptoms [14, 17]; thus, remitted depression (RD) is defined as the absence of depressive symptoms and the return to the patient's basal functioning [19].

Since there is no specific parameter to define depression in remission, previous studies have used Hamilton scale of 17 items, with a score of 7 points or less, as a criterion [20].

Some studies report the efficiency of cognitive rehabilitation using computer programs, for those patients with attention and concentration deficits. Trials like the one performed by Slate, Meyer, Burns, and Montgomery [21] used Captain's Log Computerized Cognitive Training
Program (CLCT), and combined electroencephalogram (EEG)/ neurofeedback, to treat children with Attention Deficit Hyperactivity Disorder (ADHD).

There were four cases involved in this study of childrenwith severe emotional damage, diagnosed with psychosis and ADHD. A pre-test and a post-test design were used. All of the patients' symptoms decreased and demonstrated high levels of generalization of those skills that were the focus of treatment.

Some authors like Kotwal, Burns, and Montgomery [22] demonstrated that CLCT was able to operate changes in the brain-waves patterns measured by EEG/neurofeedback equipment. These changes were evaluated in 13 years old patients with a diagnosis of ADHD. A pre-test and post-test design were used. The patients received 35 treatment sessions where significant improvements in the symptoms were shown, and changes remained seven months after the experimental process concluded.

Reference [23] used the "Cogpack" program three times a week to schizophrenic patients who, after three months of therapy, improved cognitive functions such as verbal memory and speed processing.

Two studies carried out in 2007, and 2015 [24, 25] concluded that computerized programs enhanced cognitive functions, especially work memory in patients with schizophrenia. On the other hand, computerized programs were successfully used to reduce depressive symptomatology in patients with unipolar and bipolar depression [26]. Also, computer-assisted cognitive training was successfully employed to decrease negative symptoms in schizophrenic patients and with a schizoaffective disorder [27].

Another trial [28] showed in an experimental way that Alcor Program was efficient as a treatment for depression and in the reduction of the cognitive deterioration in patients with Major Depressive Disorder; also, it was demonstrated that the program significantly increased the patients' intellectual quotient, compared to control patients.

In a more recent study, Alvarez, Yépez, Jurado, Guerrero \& Petra [29] demonstrated that Captain's Log Cognitive Training program helped to improve the intellectual performance of patients who suffered from Obsessive Compulsive Disorder (OCD), reflected in higher cognitive flexibility, processing speed, reasoning, and intellectual quotient.

Patients with dementia can benefit from computerized cognitive training programs if the impairment is mild $[24,30]$. Other authors like Edwards et al. [31], discovered after 10year-follow-up research, that training to increase processing speed delays dementia in elderly patients. Reference [32] in 2007 found that Cogni-Fit program significantly decreased the risk of dementia in older diabetic patients.

Some authors have worked with computerized programs to rehabilitate the impairment produced by some physical illnesses. For instance, Cerasa et al. in 2013 [33] used a computer-assisted cognitive rehabilitation (RehaCom) in patients with multiple sclerosis, showing with functional magnetic resonance imaging (fMRI) an increase in activity in the posterior lobe of the cerebellum (IV) and the superior parietal lobule after cognitive training with RehaCom. This 
indicates an essential relation in the lobule IV of the cerebellum that is active in the articulatory control system.

Reference [34] observed an important increase in brain activity in fMRI in patients with multiple sclerosis who had received short-term computer-based cognitive training (8 sessions). These patients enhanced their cognitive functions compared to those patients who only received placebo. Authors observed significant changes in the activation of the posterior cingulate cortex and bilateral inferior parietal cortex; therefore, they suggest that rehabilitation produces adaptive cortical reorganization favoring better cognitive performance. After the cognitive intervention, only the group that was treated preserved the improvement in processing speed. Authors did not observe changes in brain volumes.

Since some authors have tried to explain the reason why computer-assisted rehabilitation programs may produce positive changes, several trials have been carried out. Reference [35] used fMRI on adolescents who played Tetris for three months and observed thicker cortex of some of the brain's regions which are related to visual-spatial functions. These findings may suggest that computer games can produce changes in the structure of the brain.

Other studies have shown in brain images that people who suffer from depression have hippocampal volume loss and this is associated with cognitive impairment [36].

Reference [37] pointed that MRI techniques provide information to understand behavioral improvements assessed with neuropsychological tests; for instance, reorganization in structural and functional connections, and neuroplasticity produced by cognitive rehabilitation. In the same way, it helps to comprehend changes in the brain structure that considerably benefit patients with multiple sclerosis, since rehabilitation with computer programs is a non-invasive, not pharmacologic and behavioral technique that may induce neuroplasticity to try to normalize brain functions which are reflected in cognitive and behavioral improvements.

\section{Method}

\subsection{Design}

Single-blind randomized controlled trial.

\subsection{Participants}

In this study participated university students of the National Autonomous University of Mexico (UNAM) in remitted state of depression according to the Diagnostic and Statistical Manual of Mental Disorders, 4th Edition (DSMIV) criteria [38]. The diagnosis was confirmed with the Spanish digital version of the M. I. N. I (Mini- International Neuropsychiatric Interview) [39], based on the DSM-IV and International Statistical Classification of Diseases and Related Health Problems (ICD-10). To evaluate the criteria of remitted depression, the Hamilton Depression and Anxiety Rating Scales were used. Patients with psychotic disorders, Bipolar disorder or suicidal risk were excluded. Twenty-five students were selected, however, two of them were excluded because they got hired for a job and another one did not attend the final evaluation.

All of the patients were treated with Selective serotonin reuptake inhibitors (SSRI) and were randomly assigned to two groups. The Experimental group $(n=12)$, where 9 of them were women (mean age $23.2 \pm 2.5$ years) and three men (mean age $20.0 \pm 2.0$ years), and besides the pharmacologic treatment they received cognitive training. The Control group $(n=13)$ was formed of 10 women (mean age $27.7 \pm 9.5$ years) and three men (mean age $25.0 \pm 6.1$ years), and they only received SSRI. All of them signed an informed consent form.

Table 1. Distribution of participants by group and age.

\begin{tabular}{llllllllll}
\hline \multirow{2}{*}{ Group } & Men & \multicolumn{1}{c}{ Women } & \multicolumn{3}{c}{ Total } \\
\cline { 2 - 11 } & Mean & SD & $\mathbf{n}$ & Mean & SD & $\mathbf{n}$ & Mean & SD & n \\
\hline Experimental & 20.0 & 2.0 & 3 & 23.2 & 2.5 & 9 & 22.4 & 2.7 & 12 \\
Control & 25.0 & 6.1 & 3 & 27.7 & 9.5 & 10 & 27.1 & 8.6 & 13 \\
\hline
\end{tabular}

\subsection{Instruments}

1) Remitted Depression: Hamilton Depression Rating Scales (HAM-D). The Spanish version was made in 1986 by Ramos-Brieva and has 17 items. Remission has been considered with a score of 7 or less [40]. According to Zimmerman [41], the cut-off point for remitted depression is a score of 3 to 7 points. Scores from 0-2 are considered as a better remission.

2) Anxiety: Hamilton Anxiety Rating Scale (HAM-A) was designed in 1959. Initially, it was composed of 15 items, but in 1969 some of them fused; thus, it was formed of 14 elements. Each one is valued by a score of 0 to 4 points [42].

3) Wechsler Adult Intelligence Scale (WAIS-III) [43].
4) Integrated Program of Neuropsychological ExaminationRevised Barcelona Test [44]. It is an abbreviated version, adapted for its application in Mexico [45].

\subsection{Procedure}

A psychiatrist was in charge of antidepressants. Captain's Log Computerized Cognitive-Training Program (CLCT) was used to exercise cognitive abilities [1]. CLCT was created to enhance cognitive functions like attention, concentration, memory, visuomotor coordination, abstract reasoning, logical reasoning and problem-solving skills [1]. The software has nine sections with 3 to 7 routines. It was designed as a game that motivates and entertains the patient at the same time it improves cognitive functions. Participants attended two sessions a week, of 45 minutes each, starting with memory 
units and afterward, with logical reasoning.

The treatment intervention was assessed with WAIS-III, the Integrated Program of Neuropsychological ExaminationRevised Barcelona Test, as well as the Hamilton Depression and Anxiety Rating Scales.

After six months, a second evaluation was performed using the same scales, to avoid the effects of previous learning.

\section{Statistical Analysis}

Categorical variables were presented as frequency and percentage, and dimensional variables, as the mean and standard deviation. Variables were assayed using the Analysis of variance (ANOVA) for repeated measures $2 \times 2$, with two intragroup evaluating levels (initial and final) and two intergroup levels of condition (experimental and control). The effect size was calculated using Cohen's $d$ for the changes in the experimental group [46].

\section{Results}

Anxiety-Depression

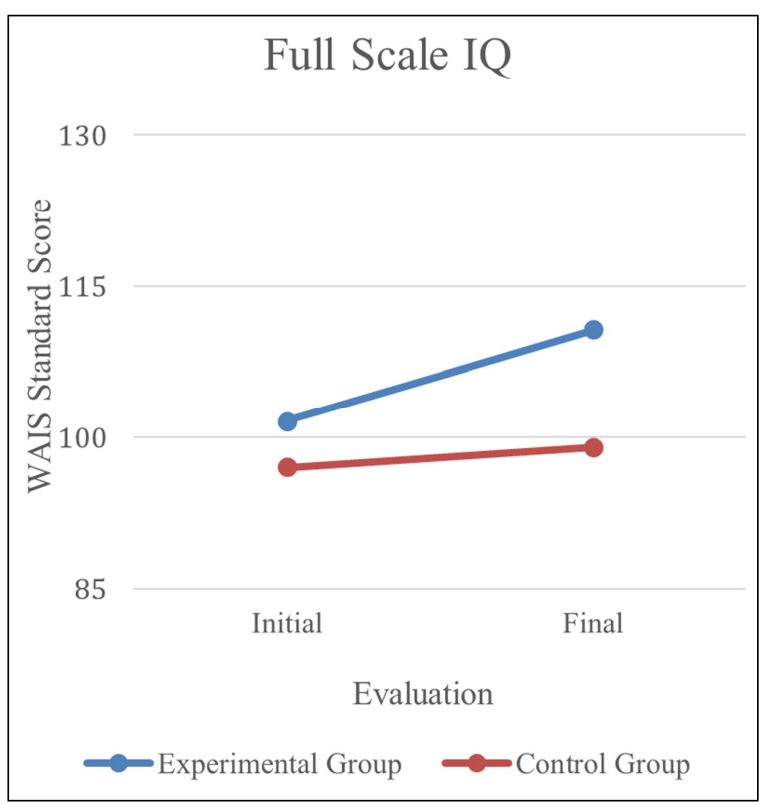

Figure 1. Full-scale IQ means by condition and evaluation.
Participants of both groups met the criterion of being depressed patients in remission and showed low anxiety scores. During the six months of evaluation, both groups decreased even more their levels of depression and anxiety, without differences between them (Table 2). As shown in Figure 1, the experimental group obtained a slightly higher IQ $(I Q=101.7)$ than the participants of the control group (IQ $=97$ ), even though they were randomly assigned. In the posttest, the IQ of the experimental was 110.7 and in the control group was 99.0

WAIS-III Intellectual Quotient (IQ)

Significant differences were found in the WAIS-III quotients. The group who received cognitive training increased Verbal IQ in 11.2 points, which represents a large size effect: $d=1.60$ [ $F$ condition $x$ evaluation $(1.23)=36.03$, $\mathrm{p}<0.001]$. Total IQ increased 9 points, considering a large size effect $\mathrm{d}=1.3$ [ $\mathrm{F}$ condition $\mathrm{x}$ evaluation $(1.23)=28.59$, $\mathrm{p}=<0.001]$ (Table 3).

WAIS-III Indexes

Significant differences were found in the WAIS Indexes; the group who received cognitive training increased the Verbal Comprehension Index by 7 points, which represents a medium size effect $\mathrm{d}=0.7 \quad[\mathrm{~F}$ condition $\mathrm{x}$ evaluation (1.23) $=5.53, p=0.028]$. The Working Memory Index increased 6.5 points, which is considered as a large size effect $\mathrm{d}=1.5[\mathrm{~F}$ condition $\mathrm{x}$ evaluation $(1.23)=30.32$, $\mathrm{p}<0.001]$. Processing Speed Index increased 10.1 points, which is a medium size effect $\mathrm{d}=0.6$ [F condition $\mathrm{x}$ evaluation $(1.23)=6.95, \mathrm{p}=0.015]$. Finally, Perceptual Organization Index showed no differences [F condition $\mathrm{x}$ evaluation $(1.23)=0.02, \mathrm{p}=0.890]$. (Table 4).

Integrated Program of Neuropsychological ExaminationRevised Barcelona Test: Subtests with significant changes

Significant differences were found in eight subtests, which are: Digit Span Forward $(\mathrm{p}=.005)$, Digit Span Backward $(p=0.01)$, Pseudoword reading Time $(p=0.001)$, Bimanual pseudogesture imitation $(p=0.001)$, Alternating sequences: right limb/hand $(\mathrm{p}=0.012)$, Alternating sequences: left limb/hand $(p=0.034)$, Story cued recall ( $\mathrm{p}=0.011)$, Digit-symbol (coding) (0.027). These results were consistent with the findings of the WAIS-III Indexes (Table 5).

(Tables are shown below).

Table 2. Distribution of participants by group and age: Depression and Anxiety means.

\begin{tabular}{|c|c|c|c|c|c|c|c|c|c|}
\hline \multirow[t]{2}{*}{ Variable } & \multirow[t]{2}{*}{ Condition } & \multicolumn{2}{|l|}{ Initial } & \multicolumn{2}{|c|}{ Interval } & \multicolumn{2}{|l|}{ Final } & \multicolumn{2}{|c|}{$\begin{array}{l}\text { Significance of Interaction } \\
\text { Condition Evaluation }\end{array}$} \\
\hline & & Mean & SD & Mean & SD & Mean & SD & $\mathbf{F}$ & $\mathbf{p}$ \\
\hline \multirow{2}{*}{ HAM-D } & Experimental & 2.33 & 0.73 & 1.25 & 0.41 & 0.17 & 0.17 & \multirow{2}{*}{0.052} & \multirow{2}{*}{0.949} \\
\hline & Control & 2.15 & 0.70 & 1.23 & 0.39 & 0.23 & 0.16 & & \\
\hline \multirow{2}{*}{ HAM-A } & Experimental & 2.75 & 0.57 & 1.75 & 0.34 & 0.67 & 0.24 & \multirow{2}{*}{1.206} & \multirow{2}{*}{0.318} \\
\hline & Control & 1.61 & 0.53 & 0.85 & 0.32 & 0.23 & 0.23 & & \\
\hline
\end{tabular}


Table 3. Distribution of participants by groups and age for the WAIS-III IQ Mean.

\begin{tabular}{|c|c|c|c|c|c|c|c|}
\hline \multirow{3}{*}{ Variable } & \multirow{3}{*}{ Condition } & \multicolumn{4}{|c|}{ Evaluation } & \multirow{2}{*}{\multicolumn{2}{|c|}{$\begin{array}{l}\text { Significance of Interaction } \\
\text { Condition Evaluation }\end{array}$}} \\
\hline & & \multicolumn{2}{|c|}{ Initial } & \multicolumn{2}{|l|}{ Final } & & \\
\hline & & Mean & SD & Mean & SD & $\mathbf{F}$ & $\mathbf{p}$ \\
\hline \multirow{2}{*}{ Verbal Iq } & Experimental & 99.3 & 7.0 & 110.5 & 6.9 & \multirow{2}{*}{36.03} & \multirow{2}{*}{$<0.001$} \\
\hline & Control & 96.3 & 5.8 & 97.5 & 6.0 & & \\
\hline \multirow{2}{*}{ Performance Iq } & Experimental & 106.5 & 6.3 & 112.4 & 5.6 & \multirow{2}{*}{6.93} & \multirow{2}{*}{0.015} \\
\hline & Control & 101.8 & 4.3 & 104.1 & 5.5 & & \\
\hline Full Scale Iq & Experimental & 101.7 & 7.0 & 110.7 & 6.5 & 28.59 & $<0.001$ \\
\hline
\end{tabular}

Table 4. Distribution of participants by group and age: WAIS-III Indexes Mean.

\begin{tabular}{|c|c|c|c|c|c|c|c|}
\hline \multirow{3}{*}{ Variable } & \multirow{3}{*}{ Condition } & \multicolumn{4}{|c|}{ Evaluation } & \multirow{2}{*}{\multicolumn{2}{|c|}{$\begin{array}{l}\text { Significance of Interaction } \\
\text { Condition Evaluation }\end{array}$}} \\
\hline & & \multicolumn{2}{|l|}{ Initial } & \multicolumn{2}{|l|}{ Final } & & \\
\hline & & Mean & SD & Mean & SD & $\mathbf{F}$ & $\mathbf{p}$ \\
\hline \multirow{2}{*}{ Verbal Comprehension Index } & Experimental & 112.8 & 9.9 & 119.8 & 6.6 & \multirow{2}{*}{5.53} & \multirow{2}{*}{0.028} \\
\hline & Control & 110.2 & 8.9 & 112 & 8.1 & & \\
\hline \multirow{2}{*}{ Perceptual Organization Index } & Experimental & 112.8 & 11 & 117.9 & 7.4 & \multirow{2}{*}{0.02} & \multirow{2}{*}{0.89} \\
\hline & Control & 102.5 & 10.4 & 107.2 & 10.2 & & \\
\hline Working Memory Index & Experimental & 98.3 & 4.3 & 104.8 & 4.8 & 30.32 & $<0.001$ \\
\hline \multirow{2}{*}{ Processing Speed Index } & Experimental & 124.3 & 17.7 & 134.3 & 11 & \multirow{2}{*}{6.95} & \multirow{2}{*}{0.015} \\
\hline & Control & 119.5 & 11.8 & 116.8 & 12.4 & & \\
\hline
\end{tabular}

Table 5. Distribution of participants by group and age: Integrated Program of Neuropsychological Examination-Revised Barcelona Test Subtests Means.

\begin{tabular}{|c|c|c|c|c|c|c|c|}
\hline \multirow{3}{*}{ Variable } & \multirow{3}{*}{ Condition } & \multicolumn{4}{|c|}{ Evaluation } & \multirow{2}{*}{\multicolumn{2}{|c|}{$\begin{array}{l}\text { Significance of Interaction } \\
\text { Condition Evaluation }\end{array}$}} \\
\hline & & \multirow{2}{*}{$\begin{array}{l}\text { Initial } \\
\text { Mean } \\
\end{array}$} & & \multicolumn{2}{|l|}{ Final } & & \\
\hline & & & SD & Mean & SD & $\mathbf{F}$ & $\mathbf{p}$ \\
\hline \multirow{2}{*}{ Digit Span Forward } & Experimental & 5.2 & 0.7 & 6.3 & 0.9 & \multirow{2}{*}{9.59} & \multirow{2}{*}{0.005} \\
\hline & Control & 4.9 & 0.5 & 5.1 & 0.5 & & \\
\hline \multirow{2}{*}{ Digit Span Backward } & Experimental & 3.9 & 0.9 & 5.5 & 1.2 & \multirow{2}{*}{7.78} & \multirow{2}{*}{0.01} \\
\hline & Control & 3.2 & 0.7 & 3.7 & 0.6 & & \\
\hline Pseudoword reading time & Control & 13.7 & 1.8 & 13.2 & 1.6 & 16.16 & 0.001 \\
\hline \multirow{2}{*}{ Bimanual pseudogesture imitation } & Experimental & 7.1 & 0.8 & 8.0 & 0.0 & \multirow{2}{*}{14.29} & \multirow{2}{*}{0.001} \\
\hline & Control & 7.7 & 0.5 & 7.5 & 0.7 & & \\
\hline \multirow{2}{*}{ Alternating sequences: right limb/hand } & Experimental & 6.9 & 0.8 & 7.7 & 0.5 & \multirow{2}{*}{7.45} & \multirow{2}{*}{0.012} \\
\hline & Control & 7.2 & 0.8 & 7.2 & 0.4 & & \\
\hline Alternating sequences: left limb/hand & Experimental & 7.0 & 1.0 & 7.7 & 0.5 & 5.09 & 0.034 \\
\hline \multirow{2}{*}{ Story cued recall } & Experimental & 19.3 & 2.6 & 21.4 & 1.1 & \multirow{2}{*}{7.55} & \multirow{2}{*}{0.011} \\
\hline & Control & 18.9 & 1.6 & 18.6 & 2.2 & & \\
\hline \multirow{2}{*}{ Digit-symbol (coding) } & Experimental & 47.3 & 4.7 & 53.5 & 6 & \multirow{2}{*}{5.61} & \multirow{2}{*}{0.027} \\
\hline & Control & 39.2 & 6.5 & 40.3 & 5.6 & & \\
\hline
\end{tabular}

\section{Discussion}

Depressed patients remained with remitted symptomatology, showing no significant differences among them. Both groups decreased anxiety levels.

Pharmacologic treatment, as well as cognitive training using CLCT, were able to maintain or modulate the remission in patients with depression; however, those who only received pharmacologic treatment did not show changes in their cognitive functions, even though they remained in remission.

Regarding intellectual performance, participants of the experimental group showed significant differences after the treatment, since their IQ increased 9 points, meanwhile control group only increased 2. This pattern seems to be repeated in Verbal IQ as well as in Performance IQ, which may be because participants who received cognitive training had better performance and obtained a bonus time in some of the WAIS-III subtests; this was probably produced by the decreased in the delay of processing that depressed patients may show. On the other hand, patients of control group seemed to have the same cognitive impairments they presented in the first evaluation.

Patients who received cognitive training reflected an increase in Verbal IQ, which indicates that they enhanced their skills to use the knowledge previously stored to judge and solve problems that require abstraction of the relations between two different elements, as well as comprehension and concept formation. In the same way, they enhanced their 
deductive reasoning skills, which is essential in their academic productivity.

The changes found in the Performance IQ of the experimental group demonstrates that the intervention is effective in training skills that are related to visual analysis (detection of missing small details from a whole); this requires sustained attention, associative thinking skills, and eye-hand coordination velocity. Significant improvements were found in visuospatial ability, integration of tridimensional designs, sequencing skills as well as in planning skills, selection, and self-regulation of answers and receive feedback on the learning to solve practical problems. This aspect is relevant since college students who continued attending classes formed the sample, and compared to the control group, there were no changes in their executive functions.

The increase of the Full-Scale IQ indicates that the students who received cognitive training showed a better development of strategies to solve problems that require verbal communication abilities as well as practical problemsolving skills that they may use in their academic life.

Regarding WAIS-III Indexes, significant differences were found in the Verbal Comprehension Index, which reiterates a better aptitude of the patients of the experimental group to understand, handle and solve problems related to the management of the language and long-term memory skills, compared to the results of the control group.

In the Working Memory Index, the experimental group demonstrated significant changes in the ability to store and retrieve new information. It should be mentioned that although the stimuli became more complicated, the subjects of the experimental group managed to evoke a higher number of stimuli, compared to the performance of the control group. These are very important since short-term memory skills are one of the functions that are most affected by depression.

The other Index that presented relevant changes was the Processing Speed Index. It is worth mentioning that these skills were favored since all the exercises that are carried out in CLCT require time control, which caused a more agile response. Thus, the participants who received the program showed an increase in the Verbal IQ, in the Performance IQ and the Full-Scale IQ; this may be due to patients receiving time bonuses on some of the WAIS-III subtests, probably produced by the reduction in the psychomotor retardation observed in depressed patients.

In the Integrated Program of Neuropsychological Examination-Revised Barcelona Test, consistent results with those demonstrated by the experimental group in the WAISIII. For instance, better ability to retain and evoke information, understanding of verbal concepts, as well as showing greater cognitive flexibility, and attentional supervision, enhancing their decision making when solving problems that the computer program presented to them, an essential aspect since they are skills that these subjects could replicate in their school environment.

This may be associated to the results obtained by Jaeggi, Buschkuel, Jonides, and Perrig in 2008 [47], which proved that skills trained with cognitive software that increases intellectual performance could be transferred and improve academic productivity and daily life problem-solving skills.

All of these results may be associated with the hippocampal volume loss that non-treated depressed patients present and that is demonstrated with MRI, according to authors like Sheline, Gado y Kraemer, in 2003 [36]. The hippocampus is an essential structure regarding memory process. On the other hand, according to the results obtained by Eriksson et al. [48], it is known that the dentate gyrus of the hippocampus produces new neurons in the adult. These cells migrate to the cortex, based on the criterion of being "used or discarded" in the prefrontal, posterior, parietal and inferior temporal cortex. It is also known that many of the cellular mechanisms that occur during learning process and consolidation, some of the structures of the central nervous system have in common significant changes in synaptic transmission, as well as morphological changes in nerve cells, according to the results obtained by Prado and Bermúdez in 2001 [49], as well as the changes in the cerebral architecture obtained by Chiaravalloti, Genova and DeLuca in 2015 [37].

It is fundamental to highlight that depressed patients who are in remission remain with cognitive impairment; from this perspective, it is possible to realize and understand the importance of rehabilitation of cognitive functions of patients who have suffered from depression to obtain an accurate remission that will definitively improve their quality of life.

Limitations

These results are only valid for university students with remitted depression; therefore, it lacks external validity. It is necessary to replicate this research with adults or seniors with depression in remission.

\section{Conclusion}

Several trials have found that college education stressors may boost depressive symptomatology and intensify as the academic demands increase, affecting basic cognitive skills, such as attention, concentration, cognitive flexibility when solving problems, motivation, and functions related to shortterm memory.

This study was able to show that cognitive training detected significant differences in students who participated in the intervention, in relation to the control group, since the experimental group not only enhanced the executive functions that are already reported in the literature but also functions related to verbal concepts management.

Since sustained attention was improved with cognitive training, participants could also improve comprehension skills for solving practical problems, optimizing processing speed. This aspect seems to be encouraging since one of the main complaints of depressive patients is slowing down during task execution.

The significant change in the results of the tasks related to the short-term memory of the experimental group also seems to be encouraging for future interventions with college 
students with academic issues, since skill retention is essential in the daily chores of any university student.

The obtained results showed quantitative significant differences as well as relevant qualitative changes, which were reported by the experimental group at the end of the treatment, where patients answered a brief survey to know about the changes they could experience throughout treatment. Patients reported a substantial enhancement in the necessary skills for learning, such as sustained attention, memory, and concentration, which were reflected in a better academic productivity and motivation. They also reported improving the agility in the daily life problem-solving.

Another highlighted aspect is that there was not found any significant decline in any of the groups since all the participants were students who attended to classes and with remitted depression; however, results showed that participants who received cognitive training improved their intellectual performance and their quality of life too.

\section{Acknowledgements}

This study was not funded by any grants. We want to express gratitude to the following individuals for their contributions:

Silvia Ortíz León, Master of Medical Sciences.

Lizbeth Beltrán Hernández, Physician, for the support in the translation of the article.

\section{Conflict of Interest}

All the authors do not have any possible conflicts of interest.

\section{References}

[1] Sandford, J., Captain's Log Cognitive Trainer, Braintrain, USA. 2011.

[2] World Health Organization, Depression and Other Common Mental Disorders. 2005.

[3] Osornio, C., Palomino, G. "Depresión en estudiantes universitarios." Archivos en Medicina Familiar, 11 (1): 1-2, 2009.

[4] Heinze G., Villamil V. \& Cortés J. F. "Relapse and recurrence of depressed patients: a retrospective study." Salud Mental, 25 (1): 3-8., 2002.

[5] Manelic R. \& Ortega-Soto H. "La depresión en los estudiantes universitarios de la Escuela Nacional de Estudios Profesionales Aragón.” Salud Mental, 18 (2): 31-34, 2005.

[6] Olmedo-Buenrostro, B., Torres-Hernández, J., VelascoRodríguez, R., Mora-Brambila, A. y Blas-Vargas, L. "Prevalencia y severidad de depresión en estudiantes de enfermería de la Universidad de Colima." Revista de Enfermería Del IMSS, 14 (1): 17-22, 2006.

[7] Heiligenstein, E., Guenther, G., Hsu, K. \& Herman, K. "Depression and academic impairment in college students." Journal of American College Health, 49 (6): 299-305, 1996.
[8] Field T, Diego, M \& Sanders, C. "Adolescent depression and risk factors." Adolescence, 36 (143): 491-498, 2001.

[9] López B, González-de Cossío O, Ávila M, Teos A. "Condicionantes epidemiológicos de salud y su relación con rendimiento escolar en el primer año de la carrera de medicina, Estudio de dos generaciones." Gac Méd Méx, 146 (2):81-90, 2009.

[10] Furr R, Westefeld S, McConnell N, Jenkins M. "Suicide and depression among college students: A decade later." Professional Psychology Research Practice, 32: 97-100, 2001.

[11] Austin, M., Mitchel, P., \& Goodwin, G. "Cognitive deficits in depression: possible implications for functional neuropathology." British Journal of Psychiatry, 178:2002006, 2001.

[12] Paelecke- Habermann, Y., Pohl, J. \& Leplow, B. “Attention and executive functions in remitted major depression patients." Journal of Affective Disorders, 89: 125-135, 2005.

[13] Sobin, C., Sackeim, H., Mann, J. \& Thase, M.” Psychomotor symptoms of depression." American Journal of Psychiatry: 154, 4-17, 1998.

[14] Weiland- Fiedler, P., Erickson, K., Waldeck, T., Luckenbaugh, A., Pike, D., Bonne, E. "An evidence for continuing neuropsychological impairments in depression." Journal of Affective Disorders, 82: 253-258, 2004.

[15] Christopher, G. \& MacDonald, J. "The impact of clinical depression on working memory", Cognitive Neuropsychiatry, 10 (5): 379-399, 2005.

[16] Mintz J, Mintz L, Arruda M, Hwang S. "Treatments of depression and the functional capacity to work." Arch Gen Psychiatry. Oct; 49 (10):761-768, 1992.

[17] Rapport, M., Denney, C., Chung, K \& Hustace, K. "Internalizing behavior problems and scholastic achievement in children: cognitive and behavioral pathways as mediators of outcome." Journal of Clinical Child Psychology, 30 (4): 536$551,2001$.

[18] De la Peña, F., Estrada, A., Almeida, L. \& Paez, F. "Prevalencia de los trastornos depresivos y su relación con el bajo aprovechamiento escolar en estudiantes de secundaria." Salud Mental, 22 (4): 9-13, 1999.

[19] Keller, M. "Past, present and future directions for defining optimal treatment outcome in depression: remission and beyond." JAMA. 289 (31): 52-60, 2003.

[20] Zimmerman M., Posternak M., Chelminski I. "Heterogeneity among depressed outpatients considered to be in remission." Compr Psychiatry, 48:113-7, 2007.

[21] Slate, S. Meyer, T. Burns, W. Montgomery, D. “Computerized cognitive training for severely emotionally disturbed children with ADHD." Behavior modification, July; 22 (3): 417-437, 1998.

[22] Kotwal, D., Burns, W. \& Montgomery, D. "Computer-assisted cognitive training for ADHD: A case study." Behavior Modification, 20 (1): 85-96, 1996.

[23] Sartory, G., Zorn, C., Groetzinger, G. y Windgassen, K. "Computerized Cognitive remediation improves verbal learning and processing speed in schizophrenia." Schizophrenia Research. 75: 219-223, 2005. 
[24] McGurk, S., Twamley, E., Sitzer, D., McHugo, G., Mueser, K. "A Meta-Analysis of Cognitive Remediation in Schizophrenia.” Am J. Psychiatry. Dec; 164 (12): 1791-1802, 2007.

[25] Cortese, S. Ferrin, M., Brandeis, D., Buitelaar, J., Daley, D., Dittmann, R., Holtman, M., Santosh, P., Stevenson, A., Sonuga-Barke, E. "Cognitive Training for Attention Deficit Hyperactivity Disorder: Meta-Analysis of Clinical and Neuropsychological Outcomes from Randomized Controlled Trials." J Am Acad Child Adolesc Psychiatry, 54 (3): 164-174, 2015.

[26] Preiss, M., Shatil, E., Cermákova, R., Cimeranova, D. \& Ram L. "Personalized Cognitive training in Unipolar and bipolar disorder: a study of cognitive functioning." Frontiers in Human Neuroscience. (7) (Article 108): 1-10, 2013.

[27] Bellucci, D. Glaberman, K., Haslam, N. "Computer-assisted cognitive rehabilitation reduces negative symptoms in the severely mentally ill." Schizophrenia Research, 59: 225-232, February 2003.

[28] Álvarez, L., Cortés, J., Ortiz, S., Estrella, J., Sánchez, J. "Computer program in the treatment for major depression and cognitive impairment in university students." Computers in Human Behavior, 24: 816-826, 2008.

[29] Álvarez L., Yépez N., Jurado M., Guerrero J., Petra I. "Stimulation of Cognitive Functions in University Students with Obsessive Compulsive Disorder Using Captain's Log Computerized Cognitive Training Program." American Journal of Applied Psychology. 7 (1): 1-10, 2018.

[30] Hill, N., Mowzowski, L., Naismith, S., Chadwick, V., Valenzuela, M., Lampit, A. (2017). "Computerized Cognitive Training in Older Adults with Mild Cognitive Impairment or Dementia: A Systematic Review and Meta-Analysis." $\mathrm{Am} \mathrm{J}$ Psychiatry. Apr 1; 174 (4), 2017.

[31] Edwards, J., Xu, H., Clark, D., Guey, L., Ross, L., Unverzagt, F. "Speed of processing training results in lower risk of dementia." Alzheimer's \& Dementia: Translational Research \& Clinical Interventions. 3:603-611, Nov 2017.

[32] Bloom, R., Schnaider-Beeri M, Ravona-Springer R. "Computerized Cognitive Training for Older Diabetic Adults at Risk of Dementia: Study Protocol for a Randomized Controlled Trial." Alzheimer's \& Dementia: Translational Research \& Clinical Interventions 3.4: 636-650. PMC. Web. Feb. 2018.

[33] Cerasa, A., Gioia, M., Valentino, P., Nistico, R., Chiriaco, C., Pirritano, D., Tomaiolo, F., Magnone, G., Trotta, M., Talarico, T. "Computer-assisted cognitive rehabilitation of attention deficits for multiple sclerosis: a randomized trial with fMRI correates." Neurorehabil Neural Repair. 27 (4):284-95, 2013.

[34] Bonavita, S., Sacco, R., Della Corte, M., Esposito, S., Sparaco, M., d'Ambrosio, A. "Computer-aided cognitive rehabilitation improves cognitive performances and induces brain functional connectivity changes in relapsing remitting multiple sclerosis patients: an exploratory study." J Neurol. 262 (1):91-100, 2015.
[35] Haier, R., Karama, S., Leyba, L., Jung, R. "MRI assessment of cortical thickness and functional activity changes in adolescent girls following three months of practice on a visual-spatial task." BMC Research Notes 2:174, 2009.

[36] Sheline Y, Gado M \& Kraemer H. "Untreated Depression and hippocampal volume loss." American Journal of Psychiatry 160 (8): 1516-1518, 2003.

[37] Chiaravalloti, N. Genova, H., DeLuca, J. "Cognitive Rehabilitation in Multiple Sclerosis: The Role of Plasticity." Front Neorol. 6:67, 2015.

[38] American Psychiatric Association. Diagnostic and Statistical Manual of Mental Disorders DSM-5. American Pychiatric Publishing. Washington, London, 2013.

[39] Heinze G., Villamil V. \& Cortés, J. F. "Relapse and recurrence of depressed patients: a retrospective study." Salud Mental, 25 (1): 3-8, 2002.

[40] Ramos-Brieva, J. C., "A new validation of the Hamilton Rating Scale for Depression". J Psychiatr Res (22): 21-28, 1988.

[41] Zimerman, M. Martínez, J., Attiullau, N., Friedman, M., Toba, C. Boerescu, D. "Why do some depressed outpatients who are in remission according to the Hamilton Depression Rating Scale not consider themselves to be in remission?" J Clin Psychiatry, 73: 790-795, 2012.

[42] Hamilton, M. "Diagnosis and rating of anxiety. In Studies of Anxiety, Lander, M. H.” Brit Journal Psychiat Spec Pub. 3:76-79, 1969.

[43] Wechsler D. Escala Wechsler de Inteligencia para Adultos. WAIS-III. Manual Moderno. 218, México, 2018.

[44] Peña-Casanova, J. Test Barcelona-R: Teoría e interpretación. Masson Segunda Edición. Barcelona, 2007.

[45] Villa, R. M. Programa Integrado de exploración Neuropsicológica. Test Barcelona R. Versión abreviada. Adaptación para la Aplicación en México. Facultad de Estudios Superiores (FES), Zaragoza. Universidad Nacional Autónoma de México (UNAM), 1999.

[46] Cohen, J. Statistical Power Analysis for the Behavioral Sciences, Hillsdale, 2nd Edition, N. J.: Lawrence Erlbaum, 1988.

[47] Jaeggi, S., Buschkuehl, M., Jonides, J., Perrig, W. "Improving fluid intelligence with training on working memory." Proc Natl Acad Sci USA, 105 (19), May 2008.

[48] Eriksson, S., Perfilieva, E., Bjöjk- Eriksson, T., Alborn, A., Nordborg, C., Peterson, A. "Neurogenesis in the adult human hippocampus." Nature Medicine, 4 (11), 1313 1317, 1998.

[49] Prado, R. \& Bermúdez, F. Memoria: dónde reside y cómo se forma, Trillas, México, 2001, pp.157. 